\title{
The Role of Moral Imagination in Patients' Decision-Making
}

\author{
KJETIL ROMMETVEIT* \\ University of Bergen, Bergen, Norway \\ JACKIE LEACH SCULLY \\ Newcastle University, Newcastle upon Tyne, UK \\ ROUVEN PORZ \\ Bern University Hospital Inselspital, Bern, Switzerland

\begin{abstract}
*Address correspondence to: Kjetil Rommetveit, PhD, Centre for the Study of the Sciences and Humanities, University of Bergen, Allegt. 34, 7800 Bergen, Norway. E-mail: kjetil.rommetveit@svt.uib.no
\end{abstract}

\begin{abstract}
This article reviews recent developments within a number of academic disciplines pointing toward an increasing importance of imagination for understanding morality and cognition. Using elements from hermeneutics and metaphor theory, it works toward a framework for a more context-sensitive understanding of human agency, especially focusing on moral deliberation and change. The analytic framework is used to analyze the story of a patient making tough decisions in the context of prenatal diagnosis. We show how a relatively stable outlook on the world, here called the "baseline of choice," is challenged by unexpected events and how imaginative processes enter into the active creation of a new moral order. The ensuing interpretation is then placed within a broader philosophical landscape. John Dewey's notion of "dramatic rehearsal" is put forward as one particularly promising way of understanding moral imagination, deliberation, and decision-making.
\end{abstract}

Keywords: bioethics, choice, deliberation, imagination, John Dewey, moral change, patients' perspectives, prenatal diagnosis

\section{INTRODUCTION}

During the past 30 years, the discipline of bioethics has come to play a prominent role in commenting on and framing decision-making processes in health care and life science research. Still, significant doubts remain

(C) The Author 2013. Published by Oxford University Press, on behalf of the Journal of Medicine and Philosophy Inc. All rights reserved. For permissions, please e-mail: journals.permissions@oup.com 
regarding the adequacy of its models of agency and decision-making processes, especially in terms of moral change. Although bioethics is a diverse field, this inadequacy may be particularly acute in situations where models are imported from analytic philosophy. Although there seems to be no lack of critique directed at some of the central presuppositions laid down in works such as Principles of Biomedical Ethics by Beauchamp and Childress (2012), alternative models of decision making and change somehow fail to engage the minds of most bioethicists or policy makers. The main paradigm presented by bioethics textbooks-in what we will refer to as "mainstream" bioethics - remains that of the rational actor basing his/her choices on sound scientific advice, thereby optimizing health and well-being through the exercise of autonomy (cf. Veatch, 1984; Ahronheim, Moreno, and Zuckerman, 2000; Freeman and McDonnell, 2001). Although not wanting to enter into a detailed discussion of the adequacy or shortcomings of such models, we nevertheless wish to provide an alternative account of decision-making and moral change, oriented toward the point of view of the patients involved in clinical settings. We base our account on the presupposition that imagination in most cases plays a far more central role to moral deliberation and change than is commonly recognized within mainstream bioethics (either "principled" or empirical approaches). Because representations of past and present situations, as well as prospective action, come with moral impact for the agents involved, we argue for an ethical understanding of "moral imaginations." A focus on moral imagination is considered important to better understand the complexity of patients's biomedical choices, providing more plausible descriptions of the decision-making process and moral change. In this text, we show, using one concrete case, how imagination plays a decisive role in the moral change of one patient facing difficult choices. While underlining that we are not really putting forward a theory here, we nevertheless introduce some concepts that can be used for grasping such processes. We also use these to reflect on the implications of our results for understanding moral context within hermeneutically oriented philosophies. In addition, we think that our approach adds an important didactic value in understanding moral deliberation and change in medical contexts from the perspective of lay persons and patients. Finally, we place our analysis within a pragmatic analytic framework of action with reference to John Dewey's notion of "dramatic rehearsal."

\section{THE RELEVANCE OF IMAGINATION}

Let us begin with a brief look at the theoretical side. Although rarely discussed as such within bioethics, a growing literature from a number of fields provides evidence for our claims about the central role of the imagination for agency and the decision-making process. The (alleged) antagonism 
between reason and imagination is indeed nothing new; it lies at the very heart of the relationship between Romanticism and the Enlightenment, so central to the western intellectual tradition (cf. Berlin, 2006; Rorty, 2007). Throughout the 20th century, many of the Romantic views were reinterpreted by philosophers of hermeneutics and pragmatics (cf. James, 1950; Gadamer, 1960; Ricoeur, 1977; MacIntyre, 1984; Dewey, 1922), often placing explicit emphasis on various functions of the imagination for reason and morality (cf. Castoriadis, 1987; Tuan, 1989; Fesmire, 2003; Elliot, 2005). In addition, and partly building on these traditions, novel approaches are now emerging within cognitive linguistics, analyzing the work of the imagination mainly through recourse to the concept of metaphor (Lakoff and Johnson, 1980; Lakoff, 1993; Johnson, 1994). Recently, strong claims have been put forward that central concepts, that is, "the metaphors we live by," are intrinsic to the physiological processes of the neural system and the brain and so can be studied as part of neurolinguistics (Lakoff and Johnson, 1999; Feldmann, 2008). These developments may provide more concrete empirical insight into processes traditionally relegated to the realm of the theoretical, or (even) the speculative. Hence, it is claimed that ". . . work in a number of fields is converging toward the rehabilitation of imagination as a fundamental scientific topic, since it is the central engine of meaning behind the most ordinary mental events" (Fauconnier and Turner, 2003, 14-15).

A related point concerns the character of health care information. Dealing, as it does, increasingly with possible futures of real or potential patients, even the most rigorous realist cannot deny the relevance of the imagination to decisions made by patients and other users of health care services. In the light of the strong criticism of bioethical models of agency, coupled with mounting challenges for genomic and preventive medicine decision-making in years to come, a thorough focus on imagination could make important contributions to the understanding of theoretical, practical, and technological challenges.

\section{A MODEST TOPOGRAPHY OF THE IMAGINATION}

As a first approximation to the question regarding what imagination is, we may paraphrase Parmenides: "Consider how the absent (things) are with certainty present to thought" (quote from Castoriadis, 1997). That is, the imagination makes present to us that which is absent by giving to it shape and form (Kant, 1968, A 118). Another way of phrasing this would be that the imagination oscillates between the real (or factual) and the possible. In the words of Dewey, "imaginative vision elicits the possibilities that are interwoven with the texture of the actual" (Dewey, quoted in Fesmire, 2003, 68). By itself, it is intimately bound up with the exploration of possible action and with choices between differing possible courses of action. In situations 
of great moral difficulty, the "possible" emerges as an imaginative response to a situation in which the moral agent seems (to him-/herself) to be stuck in what the Greeks termed an aporetic situation, that is, great perplexity and doubt. In the sections that follow, we briefly describe some prominent forms through which the imagination can be conceptualized: image, metaphor, social imaginary, and narrative. We use these concepts to describe some basic features of the broader concept of imagination.

By images, we mean something akin to common notions of imagination: images that people see "in their mind's eye." As we enter into culture and start to interact and communicate with other people, we necessarily develop images of the self and of the body (cf. Mead, 1934). The body, being the precondition for perception and experience (Merleau-Ponty, 1962), cannot itself be directly grasped (cf. Jenkins, 2004). Through images, established through social interaction, our body is seen as something else. This leads us on into the realm of metaphor. Metaphor, according to Lakoff and Johnson (1980, 5), entails "understanding and experiencing one kind of thing in terms of another." It is the transfer of cognitive structure and meaning from one conceptual domain to another, in which the origin (the "source domain") is used to make sense of the new domain ("target domain"). Lakoff and Johnson (1999) also proceed from the presupposition that concepts are situated bodily. Our basic concepts, indicating phenomena such as direction, color, objects, and movement, all stem from interaction with the world and other people. The expressions "I go through the door" and "the cat is on the mat" are not metaphorical. But when concepts are transferred to domains of experience other than the ones in which they arose, concept and experience are no longer identical and the phenomenon of metaphor arises. Thus, the expression "I go through a hard time" is based on metaphorical reasoning. Knowledge of the physical act of passing through something (a door) has been transferred to a more complex setting, including one's emotional state. The metaphor resides in the shared structure possessed by the two phenomena, centrally the image of a relatively stable structure (a door or an emotional state) through which one passes. The work of the imagination here consists in the drawing of inference patterns between the two domains of experience, and the general conceptualization of this process is accomplished in the form of an image. Thus, says Lakoff (1993, 229), "abstract reasoning is a special case of image-based reasoning."

Passing from individual consciousness to that of the collective brings us to the concept of social imaginaries. A social imaginary must be sufficiently stable to make up a relatively coherent outlook on the world, including conceptions of moral order. When shared by a sufficient number of agents, the social imaginary becomes social reality. According to Charles Taylor, such ordering of reality can be grasped as ". . . the ways people imagine their social existence, how they fit together with others, how things go on between them and their fellows, the expectations that are normally met, and 
the deeper normative notions and images that underlie these expectations" (Taylor, 2004, 23).

Images, metaphors, and imaginaries can be articulated through narratives. Everybody has an intuitive understanding of narration coming from their acquaintance with fairy tales, novels, and fantastic stories. According to Aristotle's Poetics, narrative is the imitation of action structured into a (relatively) coherent beginning, middle, and end. However, that is not all there is to it: parallel to the claim that metaphor is not something used in poetry or rhetoric only, but rather constitutive of the way we think, the claim from hermeneutic and other philosophers has been that narrative structure is constitutive of the ways in which we exist as human beings in the world (cf. Gadamer, 1960; Ricoeur 1990). There is almost no way of making sense of any situation without telling the story of the events that led to it: "I arrived on the midday train from Oslo"; "He made me do it"; "Because of poverty, most of my family emigrated to the United States in the early 20th century." We exist within complex webs of events and situations, and we make sense of the world and ourselves through the stories we tell about these. Paul Ricoeur described narrative as the active effort to bring coherence and structure into human life through the temporal ordering of actions, characters, and events. The moral relevance of this should be clear: according to MacIntyre, I can only answer the morally loaded question "What am I to do" if I can answer the prior question "Of what story or stories do I find myself a part?" (MacIntyre, 1984, 216) Narratives, then, can be seen as a moral medium, weaving interactive and intersubjective structures of meaning from the available metaphors, images, and social imaginaries.

\section{A PRENATAL DECISION STORY: THE CASE OF KATRIN}

We now apply these theoretical concepts to our patient's story. Clearly, we cannot really provide a patient's story because we are not the patients ourselves. In the paragraphs that follow, the reader finds our interpretation of one of our interviewee's interpretation of what has happened to her. It is our own narrative of her narrative, a double hermeneutic approach (cf. Giddens, 1984; Smith, 2003) to illustrate what we think can be understood as the working of "moral imagination" in her decision-making process. At the end of the narrative, we will especially focus on a key metaphor in her story, a "metaphorical image" that seemed to help her cope with the moral implications of her situation.

The story that we take as our example comes from a qualitative interview study conducted in Switzerland between 2002 and 2006. The story takes place within the context of prenatal testing. It deals with a woman's experiences undergoing a difficult situation of prenatal diagnosis. We call this woman Katrin. Katrin was interviewed by two of us in Basel, Switzerland, 
in the spring of 2004. The semistructured interview questions focused on her experiences of prenatal diagnosis, her decision-making process, and her coming to terms with the results. At the time of the interview, the questions did not specifically probe for images or imagination but for time as a factor in the patient's decision-making process. Our research interest in imagination evolved later, and thus, in an additional round of interpretation, we reconsidered her decision-making process story in an additional round of interpretation considering the concepts outlined above.

Katrin, aged 44 at the time of the interview, explained that she had gone through her first pregnancy at the age of 38 but that there was a miscarriage. She then became pregnant again the same year, this time with twins. The pregnancy worked out well and both twins were born healthy. After the birth of the twins, she immediately became pregnant again. But when she went through ultrasound screening as part of a routine prenatal checkup, a serious problem emerged: an enlarged neck fold, which can be an indicator of a chromosomal defect and thus of a potential disability in the coming child, was spotted on the screen. She was immediately offered a chorionic villus biopsy to identify potential genetic causes of the enlarged neck fold. In the interview, Katrin emphasized that she had already reflected upon the possibility of having a disabled child. She explained that:

In the case of Down syndrome, it would not be sufficient reason for an abortion, that was for me like a norm. I told my husband that [people with Downs] can take part in society, they can lead their own lives, they are absolutely capable of living their lives.

Her prior knowledge and thinking led her to suspect that what had been detected was indeed Down syndrome. However, her doctor thought it might be something else:

Then the chorionic villus biopsy was done and the doctor told me, with this size of neck fold I would have to expect a bad result, he had to tell me that, and he said that in two to three days I would know for sure. And I asked him: 'Okay, what do I have to consider? Is it Down syndrome?' 'No, it can't be that, if it was, the neck fold would not be so thick, it must be something else, probably worse.' 'Okay, what would that be?' 'Maybe Turner syndrome.' And I had no idea what Turner Syndrome might be.

Then-she went on to explain in the interview-she waited for the test result for two days. Her fetus was then diagnosed as being affected by neither Down syndrome nor Turner syndrome, but by Trisomy 13. Trisomy 13 is a chromosomal defect that is invariably lethal to the child. From a medical perspective, there was only one solution for this situation, and thus Katrin was immediately offered an abortion.

The people in the hospital told me to contact my gynaecologist, and he said he would sign me up for an abortion right away. I asked him: Why abortion, is there no other possibility? 
At that time, she could not imagine there being no other way out of the situation:

A very, very difficult time for me, and I constantly asked myself: do I have to abort a living child now, do I have to kill a living being?

During the interview, she also made it clear that her partner was in favor of the abortion, as was her father. But to her, the situation was too overwhelming, and it did not make sense at all:

Understanding that the child will never really live, but still, right now, it does live within me (. .), and not having the time to come to terms with that.

In this difficult situation, with no proper support from her husband or her father, an additional problem that made things much worse appeared: one of her existing twins developed a life-threatening disease and was admitted to hospital. Although Katrin emphasized in the interview that she was trying hard to be strong, considering both the uncertainty of the current pregnancy and the severely ill child, she summarized her situation retrospectively by saying that:

I knew that I could not go through this pregnancy alone (. . .) and one big factor was my exhaustion, I was so exhausted.

She then decided to give in to the offer of abortion, in order to be able to properly take care of the sick child in the hospital. In the interview, she gave us a powerful description of the moment of her final decision:

I suddenly saw myself as a mother bear, I had the image, I have to care for my offspring, they are here now. That is the important thing now, my powers, what I have left, I must use them on what is, not on what might be.

Thus, Katrin uses the image of a "mother bear" as a metaphor to describe herself in that very situation. She finished the interview by emphasizing that she regretted that she had not been offered more possibilities in her difficult situation and that afterward, she had thought a lot about what it would have been like to give birth to the profoundly disabled child who would then die.

\section{RECREATING MORAL ORDER}

Imagining herself as a mother bear appeared to help Katrin reconstruct a particular version of her role as a mother, as a family member, and ultimately also as a member of society. We cannot know whether she really did visualize herself as a bear exactly at the moment of the decision. Perhaps, she only used this image retrospectively in the interview, as a powerful metaphor to describe her former feelings and emotions. However, taking her statement at face value, we want to argue that the image and her identification with it might have provided her with moral guidance, and possibly 
also with much-needed motivation, for how to proceed. Of course, we are not claiming that the image arose in some way independent of Katrin's own moral deliberations. Rather, we suggest that she was able to create a new moral order for herself by imaginatively projecting her knowledge of "bearhood" and her connotations of that metaphor onto herself and her situation. A mother bear is a strong animal, and Katrin needed all the strength she could gather at a time of physical and emotional exhaustion. A mother bear fiercely protects her offspring when they are under attack. Katrin may have felt her unborn child to be under attack: by fate, by the doctors, and even by her husband. Nevertheless, her living children were also in danger, and the sick one in particular was in need of her protection. She then decided that ". . . my powers, what I have left, I must use them on what is, not on what can be." Then, two days before she received the final diagnosis, she had told herself to "mobilize her powers" in the face of the challenges to come, that is, to take care of the child in her womb. Thus, the image may be seen to have captured the energy already mobilized, but re-channeled it toward her other children. In our interpretation, Katrin aligns herself with those aspects of the mother bear metaphor that encompass her sense of desperation, of defiance, and of focusing on immediate concerns - the real children-as an animal would do. Hence, it is not that the image generates a solution, but that the image becomes the focal point for the creation of a new moral order. There is nothing "irrational" about the aspects highlighted in this leap of the imagination: the unborn child is important but not as important as the one in the hospital. That realization helps Katrin to reach a decision in a situation that she had never before experienced, a situation for which she lacked moral and experiential precedents: a new moral order was created by Katrin through the heuristic use of the image of the bear.

\section{REIMAGINING THE SOCIAL AND MORAL CONTEXT}

We have already started to use some of the theoretical concepts, that is, image and metaphor, in order to interpret Katrin's account of her choice. We now move toward some of the broader concepts in order to try and make more sense out of the wider context of that choice. First, we suggest that one reason why she experiences the situation as especially hard is the moral outlook she has on the world: she sees the world as holding a place for every child, including profoundly disabled ones (cf. her first quote above). This is the social imaginary within which she begins her process of choice and in which she, through narrative, makes sense of her own social role. It seems reasonable that her narrative of her moral self in that situation would go something like: "I am the kind of person who will defend the right of every child, including severely disabled ones, to be born and to have a place in society." Let us call this particular outlook on the world the baseline of her 
choice; it is the general background against which she makes sense of herself within the wider social and moral order. This order has a relatively stable form, that is, it is a social imaginary, as described earlier. Its status as a social imaginary may be seen as constituted in two ways: first, it is Katrin's specific outlook on how society and human relations are and ought to be. Second, it is a view on the world that many other people also hold: even if not universally held, it has a social and historical existence and is not restricted to the "private" morals of one person. It is realistic in the sense that it, in many cases, actually guides both individual and collective action. The moral order as imagined by Katrin corresponds to real alternatives in the real world.

However, the course of events seriously challenges her world view. The viability of that particular imaginary that is her particular version of a moral order and its corresponding narrative of self is called into question. This realization emerges from a chain of events, triggered by the diagnosis, but that by itself does not cause the crisis that Katrin experiences. Critical features of the situation change as the lack of support from her family becomes clear and when her other child, the twin, becomes seriously ill. These features ensure that Katrin feels she has few alternatives but to choose the option of termination. This she does, but she does so in a specifically creative way, one that opens up the prospect of emerging from the situation with her moral self and dignity more or less intact.

We are of course aware that we have chosen a case example that could be seen to favor the particular kind of interpretation that we are making here. Still, we believe the case of Katrin can be seen as representative of both a more general capacity of creative world making and the role of the imagination in difficult moral decisions. A situation that seems impossible in its moral implications and complexities is transformed through the image of the mother bear. In a sense, the image condenses the situation and Katrin's role in it: both are transformed in the same process. This makes a world of difference, insofar as that movement also opens up prospects for future action where previously those prospects were in conflict with Katrin's vision of her moral identity. What we termed the baseline of choice has also thereby been transformed: Katrin's social imaginary is no longer a world in which there is a place for every child and in which her role as a mother is consistent with that. Her moral self is kept intact through the focus on other morally laudable aspects of motherhood.

This observation of the reconfiguration of the greater whole through a smaller part may be seen to go against certain (rather conservative) presuppositions made by central thinkers within hermeneutic theory. Both MacIntyre (1984) and Taylor (1989, 1992, 2004) seem to presuppose the existence of a broad and general background: the social imaginary or narrative of self that resides as a lasting structure and that forms the telos of moral action and choice. This broader background cannot be changed; both MacIntyre and Taylor seem to imply the existence of a greater moral order 
that informs choice but is not greatly informed by, or changed by, individual choice. Katrin's image of the mother bear will probably not reside strongly in her everyday consciousness; it is more likely to have served as a kind of heuristic of transition for that situation. What may very well be irrevocably changed, however, is her outlook on the world as a place where there is a place for every child. This provides us with a view of the imagination as more active, more radically constitutive, of moral order than that implied by MacIntyre and Taylor. In the sense that every individual's understanding of social order contributes to the social imaginary, Katrin's mental transformation may be part of the incremental shift in the social construction of how women and mothers should respond to prenatal diagnostic technologies.

\section{JOHN DEWEY'S NOTION OF DRAMATIC REHEARSAL}

John Dewey's notion of imagination as exploratory action, further elaborated through the notion of "deliberation as dramatic rehearsal that takes place in imagination" (Dewey, 1922, 190), allows us to place this interpretation within a general framework of action. For Dewey, imagination comes through as one central element within the larger process of decision making and action (see Fesmire, 2003). Deliberation and imagination start from unexpected interference with habitual modes of behavior:

We compare life to a traveler faring forth. We may consider him first at a moment where his activity is confident, straightforward, organized. He marches on giving no direct attention to his path, nor thinking of his destination. Abruptly he is pulled up, arrested. Something is going wrong in his activity. From the standpoint of an onlooker, he has met an obstacle which must be overcome before his behavior can be unified into a successful ongoing. From his own standpoint, there is shock, confusion, perturbation, uncertainty. For the moment he doesn't know what hit him, as we say, nor where he is going. (Dewey, 1922, 181)

Following this, our everyday habits consist of relatively stable and repeated patterns of action, accompanied by notions of the world that are also stable and so remain, by and large, unexamined. We normally do not have to think about them. The central roles of both deliberation and imagination only come to the fore when such stable patterns of action, thought, and emotion come into conflict, where our course is blocked. In the case of Katrin, such a blockage developed through several stages, notably in the discovery of the enlarged neck fold and the subsequent diagnosis of the sick twin. In such situations, activity shifts from the external environment of the everyday life to the inner stage of the imagination: "activity is turned from execution into intra-organic channels, resulting in dramatic rehearsal" (Dewey, 1922, 191). On the inner stage, there appears the imaginative testing out of different courses of possible action: "Deliberation is an experiment in finding out what the various lines of possible action are really like" (Dewey, 1922, 
190). Katrin passes through two stages of "dramatic rehearsal." First, there is the situation in which she considers a number of possible diagnoses. At this stage, the medical doctors and her gynecologist set the premises of deliberation, and the implication is the (possible) "killing" of her own child. She then realizes that all the available diagnoses present her with alternatives that are likely to conflict with her moral views. In the second stage, she enters a period where she also realizes that she cannot go through with the pregnancy. The solution that emerges through the image of the mother bear accords with Dewey's description of the result of deliberation, through which the actor/agent returns to the external world and action. "This implies . . . the presence of a comprehensive object, one which coordinates, organizes and functions each factor of the situation which gave rise to conflict, suspense and deliberation" (Dewey, 1922, 195). In the case offered in this article, such an object emerged with great clarity and force, possibly in response to the urgency and gravity of Katrin's situation.

However, the creation of that image should not be mistaken for the process of deliberation itself. It is rather a spontaneous response arising from the pressure of the situation and the urgent need for action. We could say: deliberation considers and evaluates alternatives for action with relative distance and coolness and so can allow itself to play with the different options for action. At some point, however, deliberation must be cut short. In the case of Katrin, the situation is urgent and the options for choice are also strongly limited. The ensuing decision may be seen more as a reflex response than as free and reflective; indeed, it is a leap of the imagination. Taken together, they bring about a fundamental shift in moral order, that is, moral change has taken place. The image compresses the whole of the situation into one focal point sufficiently powerful to motivate and instigate action. The preceding deliberative steps enter into that process and lead up to it, but they do not determine it. The story, therefore, contains elements of deliberation, free creation, and unbending external force, and none of these can be reduced to another.

Clearly, imagination is not one thing, and visions of action may come in several forms. However, the search for relative unity of experience and action makes up a constitutive theme in many writings on the imagination. The creation of such unity can only be attained through its active use.

\section{CONCLUSION}

We started out with a number of features of the imagination: image, metaphor, narrative, and social imaginary. We then used these concepts to interpret the decision-making story of Katrin. In particular, we wanted to emphasize the role of the imagination in the constitution of moral views of self and society and for bringing about moral change: we saw how a certain 
"baseline" of choice, that is, a moral outlook on social and moral order, came into conflict with events that introduced new necessities into Katrin's life. Cast into a situation of exhaustion, despair, and moral doubt, and with rational deliberation seemingly blocked by an intractable conflict of moral incompatibles, she produced a certain solution to the problem, one in which she had to strongly revise her moral outlook on the world. The final proof of her new moral outlook emerged as she regained her capacities for action. In that sense, we may state a certain relation between autonomy as self-determination, here referring to her image of herself, and agency, understood as the capacity to act.

It may be argued that, in reality, Katrin had no real choice. In reality, she was trapped by her own body, the diagnosis given by the medical doctors, and the cultural and technological context in which she found herself. In this case, it could be argued that Katrin has not exercised autonomy in her imaginative redescription of herself but rather has made the best of a bad job: she has come to a face-saving accommodation with an act she has been forced to undertake. Yet, we would argue that prior to Katrin's redescription, the situation was an impossible dilemma of antagonistic moral imperatives. The redescription enabled Katrin to see her way forward so that her choice was congruent with her moral sense of what a mother is and does. Such congruence contributes to a strong sense of moral identity and hence agency.

The relevance for ethics should be clear. First, it made a world of difference to Katrin that she was able to actively reestablish her moral self, and in that sense, not give in to external pressure. Second, especially in cases where the determining forces are weaker than those described in this case, the active use of the imagination for deliberation is essential to what we commonly term autonomous choice.

\section{ACKNOWLEDGMENTS}

We are grateful to the reviewers whose comments helped us to improve the content of the text. We also wish to thank Christoph Rehmann-Sutter, a former colleague of JLS and RP in the study. The qualitative interview study was funded by the Swiss National Science Foundation, 2002/6.

\section{REFERENCES}

Ahronheim, J. C., J. D. Moreno, and C. Zuckerman. 2000. Ethics in Clinical Practice. Gaithersburg, MD: Aspen Publishers.

Beauchamp, T. L., and J. F. Childress. 2012. Principles of Biomedical Ethics. 7th ed. Oxford: Oxford University Press.

Berlin, I. 2006. Political Ideas in the Romantic Age: Their Rise and Influence on Modern Thought. Princeton, NJ: Princeton University Press.

Castoriadis, C. 1987. The Imaginary Institution of Society. Cambridge, MA: Polity Press. 
1997. "Radical Imagination and the Social Instituting Imaginary." In The Castoriadis Reader, edited by D. A. Curtis, 319-38. Oxford: Blackwell.

Dewey, J. 1922. Morality is Social. Human Nature and Conduct: An Introduction to Social Psychology. New York: Modern Library.

Elliot, B. 2005. Phenomenology and Imagination in Husserl and Heidegger. Abingdon, UK: Routledge.

Fauconnier, G., and M. Turner. 2003. The Way We Think. New York: Basic Books.

Feldmann, J. A. 2008. From Molecule to Metaphor: A Neural Theory of Language. Cambridge, MA: The MIT Press.

Fesmire, S. 2003. John Dewey and Moral Imagination. Pragmatism in Ethics. Bloomington, IN: Indiana University Press.

Freeman, J. W., and K. McDonnell. 2001. Tough Decisions: Cases in Medical Ethics. New York: Oxford University Press.

Gadamer, H. G. 1960. Wahrheit und Methode. Grundzüge einer Philosophischen Hermeneutik. Tübingen, Germany: Mohr.

Giddens, A. 1984. The Constitution of Society. Cambridge, UK: Polity Press.

James, W. 1950. The Principles of Psychology. New York: Dover.

Jenkins, R. 2004. Social Identity. Abingdon, Oxon: Routledge.

Johnson, M. 1994. Moral Imagination. Implications of Cognitive Science for Ethics. Chicago: Chicago University Press.

Kant, I. 1968. In Werkausgabe. Edited by W. Weischedel, A115-A130. Frankfurt am Main, Germany: Suhrkamp.

Lakoff, G. 1993. "The Contemporary Theory of Metaphor." In Metaphor and Thought, edited by A. Ortony, 202-51. Cambridge, UK: Cambridge University Press.

Lakoff, G., and M. Johnson. 1980. Metaphors We Live By. Chicago: University of Chicago Press. . 1999. Philosophy in the Flesh: The Embodied Mind and Its Challenge to Western Thought. New York: Basic Books.

MacIntyre, A. 1984. After Virtue. Notre Dame, IN: University of Notre Dame Press.

Mead, G. H. 1934. Mind, Self and Society from the Standpoint of a Social Behaviorist. Chicago: University of Chicago Press.

Merleau-Ponty, M. 1962. Phenomenology of Perception. London, UK: Routledge.

Ricoeur, P. 1977. The Rule of Metaphor: Multi-Disciplinary Studies in the Creation of Meaning in Language. Toronto, Canada: University of Toronto Press.

- 1990. Time and Narrative. Chicago: University of Chicago Press.

Rorty, R. 2007. Philosophy as Cultural Politics. Cambridge, UK: Cambridge University Press.

Smith, J. A. 2003. "Interpretative Phenomenological Analysis." In Qualitative Psychology, edited by J. A. Smith, 51-80. London, UK: Sage.

Taylor, C. 1989. Sources of the Self. The Making of the Modern Identity. Cambridge, MA: Harvard University Press. - 1992. The Ethics of Authenticity. Cambridge, MA: Harvard University Press. 2004. Modern Social Imaginaries. Durham, NC: Duke University Press.

Tuan, Y. T. 1989. Morality E Imagination. Paradoxes of Progress. Madison, WI: University of Wisconsin Press.

Veatch, R. M. 1984. Autonomy's temporary triumph. Hastings Center Report 14:38-40. 